\title{
The cost of cancer care is not related to its outcomes
}

\author{
Guy Storme ${ }^{1}$, S Dhaese ${ }^{1}$, D Corens ${ }^{2}$ and Mark De Ridder ${ }^{1}$ \\ 1Department of Radiation Oncology, UZ Brussel, Belgium \\ ${ }^{2}$ Financial Department, UZ Brussel, Belgium \\ Correspondence to: Guy Storme. Email: guy.storme@uzbrussel.be
}

\begin{abstract}
Solid tumours make up $90 \%$ of all proliferative diseases and the main action for cure remains surgery, removing the visible tumour as well as the surrounding tissue. Radiotherapy is an added value for eliminating local microscopic as well as regional disease. Systemic treatment has a small impact on the outcome but has a cost, which is as much as all the other actions such as diagnostic tools and treatments.
\end{abstract}

Keywords: cost-effectiveness, surgery, radiotherapy, systemic treatment

Published: 28/10/2016

Received: 24/05/2016

ecancer 2016, 10:687 DOI: 10.3332/ecancer.2016.687

Copyright: (c) the authors; licensee ecancermedicalscience. This is an Open Access article distributed under the terms of the Creative Commons Attribution License (http://creativecommons.org/licenses/by/3.0), which permits unrestricted use, distribution, and reproduction in any medium, provided the original work is properly cited. 


\section{Background and introduction}

The cost of health care is still increasing and the top of the bill is still not in view. New treatments, mainly that of pharmaceutical agents, are exploding [1] and are only effective at a very low level without a clear impact on the population [2].

\section{Methods}

Hospital bills of individual incoming patients $(n=637)$ at the Oncologic Centre UZ Brussel between 01 January 2006 and 30 June 2006 were individually analysed according to the different actions described and summed up to avoid too much detail: consultation, surgery, hospitalisation, day hospital, pharma, medical material, radiology, anatomopathology, clinical biology, radiotherapy, nuclear medicine.

All bills were followed for five years or until the patients died, taking also into account the cost of relapses and palliation. Individual costs such as travelling, work loss etc. were not taken into account.

\section{Results}

Table 1 shows the individual described costs in Euros of the summed up activities. The main cost is pharmaceutical agents and together with the administration of them (D Hosp) it makes up $49.7 \%$ of the total cost. Surgery being the most important curable factor, at least for solid tumours, is only $4.9 \%$ and radiotherapy $9.7 \%$. Diagnostic procedures covering radiology, anatomopathology (which is the confirmation of the exact tumour origin), clinical biology and nuclear medicine makes up $17 \%$ of the total bill. The initial cost (first year) is $53.4 \%$ of the total five-year cost and that for the fifth year is only $8.4 \%$, the latter corresponds mostly to palliative care for relapsing patients. Our patient distribution in order of localisation and percentage is: breast $22 \%$, brain (including metastatic locations $16 \%$; lung $9 \%$, prostate $9 \%$, rectum $6 \%$, head and neck $5 \%$, skin $3 \%, \ldots$ The work-up as well as the treatment was done according to international guidelines. The outcomes of our data in breast-[4-6], rectum-[7-8], head and neck-[9], lung-[10], and prostate cancer [11-12] were published in several peer reviewed papers and also at the European collaborative level [7, 13].

Table 1. Total five year cost (In Euros) for individual bills by medical activity.

\begin{tabular}{|l|c|c|c|c|c|c|}
\hline \multicolumn{1}{|c|}{ Results } & $\mathbf{2 0 0 6}$ & $\mathbf{2 0 0 7}$ & $\mathbf{2 0 0 8}$ & $\mathbf{2 0 0 9}$ & $\mathbf{2 0 1 0}$ & Total Five $\mathbf{~}$ \\
\hline SX & 285,565 & 51,845 & 32,841 & 25,459 & 24,777 & 393,486 \\
\hline Consult & 83,375 & 49,741 & 32,898 & 24,806 & 22,025 & 212,845 \\
\hline Hospit & 620,447 & 147,694 & 112,607 & 103,364 & 78,213 & $1,087,505$ \\
\hline D Hosp & 147,770 & 794,36 & 51,337 & 27,977 & 33,570 & 340,090 \\
\hline Pharma & $1,876,795$ & 690,390 & 478,294 & 295,980 & 338,022 & $3,679,481$ \\
\hline MedMat & 129,313 & 32,702 & 23,155 & 21,458 & 16,030 & 222,658 \\
\hline Radiol & 238,762 & 111,347 & 100,670 & 86,639 & 74,459 & 611,877 \\
\hline Lab AP & 140,005 & 22,921 & 18,353 & 13,436 & 14,075 & 208,789 \\
\hline ClinBiol & 116,762 & 46,379 & 27,473 & 28,510 & 22,438 & 241,563 \\
\hline Radioth & 565,927 & 81,115 & 56,014 & 50,693 & 33,610 & 787,359 \\
\hline NuclMed & 140,146 & 63,406 & 42,329 & 33,907 & 26,602 & 30,6391 \\
\hline Total & $4,317,868$ & $1,376,976$ & 975,971 & 712,229 & 683,820 & $8,092,043$ \\
\hline
\end{tabular}

List of abbreviations used

SX: surgery, Consult: consultation, Hospit: hospitalisation, MedMat: medical material, Radiol: radiology, Lab AP: laboratory anatomopathology, ClinBiol: clinical biology,

Radioth: radiotherapy, NuclMed: nuclear medecine, Pharma: pharmaceutical agents. 


\section{Discussion}

The cost of health care is rapidly increasing, mainly in the development of new drugs which have increasingly been focused on 'personalised' medicine in recent years [1]. In the period analysed, there was no major new drug reimbursed by social security and this analysis is certainly no representative of the present day increasing cost mainly because those drugs use immunomodulatory activity [17]. The positive impact of systemic treatment is limited [2]. As for example say in breast cancer,when we observe patients with taxanes and herceptine, accepted as part of routine treatment, in node positive patients on top of hormone treatment like oestrogen positive patients and also with agressive treatments in triple negative patients from 2000 on, the impact on the population is not that obvious at five years (90.1-91\%) [3]. If we evaluate precision medicine thus far in many patients $(18,000)$ who have undergone sequencing in the past decade, the number of reported cases are rare and only a few showed a complete response [14]. Moreover, the good responders were already good responders to chemotherapy.

The only proofs of the bonus of 'precision or targeted' medicine are randomised trials and the SHIVA trial. We see treating patients according to their identified mutations versus selected treatment by the physician showed no difference in progression-free survival (PFS) (2.3 veruss 2.0 months) [15]. Even if we have some long living patients like in melanoma, we need to wait longer for the impact to be seen on five year survival.

Recently the US Food Drug Administration (FDA) approved a treatment for melanoma where it shrunk $60 \%$ of tumours in a clinical trial The company charged 141,000 US dollars for the first 12 weeks and 256,000 US dollars for a year! A study of the National Bureau of Economic Research in 2015 found drug prices had increased by $10 \%$ every year between 1995 and 2013, an annual increase of around 8500 US dollars, which resulted in an average cost for one extra year of life of 54.000 US dollars in 1995, increasing to 139.000 US dollars in 2005 , and 207,000 in 2013 [16].

However, the major outcome bonus is related to shift in stage at diagnosis to screening (50\%shifted from SII to SI in breast cancer between 1989 and 1999 SEER DATA). The same is observed for colorectal cancer and prostate cancer: since 2000 no bonus has been observed (data not shown). In non-small cell lung cancer NSCLC, a bonus of $3 \%$ has been observed since 2000 , but this is perhaps because of better diagnostic tools such as PET-CT scan which is now mandatory before starting treatment. Previously, it was described that the bonus of cytotoxic chemotherapy was about 2.1-2.3\% [2] and we are now confronted with new molecules at astronomic amounts for a single treatment, of which the bonus is difficult to evaluate on population outcome so far $[1,16]$.

For most people arguing for new drugs even by trials outcome, it should be worthwhile to read the paper by L Saltz: 'The Value of Considering Cost, and the Cost of Not Considering Value' [16] and his conclusion 'We need to understand, and we must help our patients, our partners in industry, and our elected officials to understand, the meaning and importance of value, and that there must be upper limits to cost. We must recognise and then work to remove the perverse incentives that impede the healthy functioning of the cancer drug market'.

We here end with Prasad's recent thought on precision medicine: 'We can ask if rhetoric so far outpaces the reality that we risk fooling even ourselves' [18].

\section{Conclusions}

Cost effectiveness in cancer care is inversely proportional to outcome, mainly in solid tumours, which from 2000 on has had nearly no impact on the population outcome. Politicians should take this into account when reimbursing health care for cancer.

\section{Conflicts of interest}

No conflicts of interest. 


\section{References}

1. Sullivan $R$ et al (2011) Delivering affordable cancer care in high-income countries Lancet Oncol 12(10) 933-980 DOI: 10.1016/ S1470-2045(11)70141-3 PMID: 21958503

2. Morgan G et al (2004) The contribution of cytotoxic chemotherapy to 5-year survival in adult malignancies Clin Oncol 16(8) 549-60 DOI: 10.1016/j.clon.2004.06.007

3. Surveillance, Epidemiology and End Results (SEER) Program (www.seer.cancer.gov) SEER*Stat Database: Incidence - SEER 9 Regs Research Data, Nov 2014 Sub (1973-2012) Table 4

4. Voordeckers M et al (2004) The lymph node ratio as prognostic factor in node-positive breast cancer Radiother Oncol 70(3) 225-30 DOI: $\underline{10.1016 / j . r a d o n c .2003 .10 .015}$ PMID: 15064006

5. Promish D et al (2009) Survival benefit with radiation therapy in node-positive breast carcinoma patients Strahlenther Onkol 185(10) 65662 DOI: 10.1007/s00066-009-2047-z

6. Bartelink $\mathrm{H}$ et al (2015) Whole-breast irradiation with or without a boost for patients treated with breast-conserving surgery for early breast cancer: 20-year follow-up of a randomised phase 3 trial Lancet Oncol 16(1) 47-56 DOI: 10.1016/S14702045(14)71156-8

7. Engels B et al (2012) Phase Il study of preoperative helical tomotherapy with a simultaneous integrated boost for rectal cancer Int J Radiat Oncol Biol Phts 83(1) 142 -8 DOI: 10.1016/j.jirobp.2011.05.068

8. Voordeckers M et al (2012) Parotid gland sparing with helical tomotherapy in head-and-neck cancer Int $J$ Radiat Oncol Phys 84(2) 443-8 DOI: 10.1016/j.jijrobp.2011.11.070

9. Van den Begin $\mathrm{R}$ et al (2014) Impact of inadequate respiratory motion management in SBRT for oligometastatic colorectal cancer Radioth Oncol 113(2) 235-9 DOI: 10.1016/j.radonc.2014.11.005

10. Bral S et al (2010) Toxicity and outcome results of a class solution with moderately hypofractionated radiotherapy in inoperable Stage III non-small cell lung cancer using helical tomotherapy Int J Radiat Oncol Biol Phys 77(5) 1352-9 DOI: 10.1016/j. ijrobp.2009.06.075 PMID: 20056350

11. Fonteyne $\mathrm{V}$ et al (2012) Hypofractionated high-dose radiation therapy for prostate cancer: long-term results of a multi-institutional phase II trial Int J Radiat Oncol Biol Phys 15(84) 483-90 DOI: 10.1016/j.jijrobp.2012.04.012

12. Bolla $\mathrm{M}$ et al (1997) Improved survival in patients with locally advanced prostate cancer treated with radiotherapy and goserelin N Engl J Med 337(5) 295-300 DOI: 10.1056/NEJM199707313370502 PMID: 9233866

13. Prasad V and Vandross A(2015) Characteristics of exceptional or super responders to cancer drugs Mayo Clin Proc 90 1639-49 DOI: 10.1016/j.mayocp.2015.08.017 PMID: 26546106

14. Le Tourneau C et al (2015) Molecularly targeted therapy based on tumour molecular profiling versus conventional therapy for advanced cancer (SHIVA): a multicentre, open-label, proof-of-concept, randomised, controlled phase 2 trial Lancet Oncol 16 1324-34 DOI: 10.1016/S1470-2045(15)00188-6 PMID: 26342236

15. Hodi F et al (2016) Combined nivolumab and ipilimumab versus ipilimumab alone in patients with advanced melanoma: 2-year overall survival outcomes in a multicentre, randomised, controlled, phase 2 trial Lancet Oncol S1470- 2045 PMID: 27622997

16. Elkins C (2015) Posted October 7th, 2015 filed under Health and Medical Conditions

17. Saltz LB (2016) The value of considering cost, and the cost of not considering value J Clin Oncol 34(7) 659-60 DOI: 10.1200/ JCO.2015.64.7867

18. Prasad V (2016) Perspective: the precision-oncology illusion Nature 537, S63 08 DOI: 10.1038/537S63a PMID: 27602743 